\title{
Important prognostic factors for survival in patients with malignant pleural effusion
}

\author{
Mauro Musa Zamboni ${ }^{1 *}$, Cyro Teixeira da Silva $\mathrm{Jr}^{2}$, Rodrigo Baretta', Edson Toscano Cunha ${ }^{1}$ and Gilberto Perez Cardoso ${ }^{2}$
}

\begin{abstract}
Background: The approach to palliative treatment of malignant pleural effusion (MPE) should be individualized because these patients generally have poor survival. Our study aimed to develop a model to identify prognostic factors or survival time in patients diagnosed with MPE.

Methods: This is a retrospective, descriptive, observational study to identify prognostic factors related to MPE in patients with a confirmed cancer diagnosis. Cox regression analysis was used to determine significant potential prognostic factors with respect to survival time. Survival time was defined as the time from pathological diagnosis to death.
\end{abstract}

Results: One hundred and sixty-five patients were included; 77 were men (47\%) and 88 were women (53\%). The median age was 60 years, and all of the patients were pathologically proven to have MPE. Non-small-cell lung cancer (36.0\%), breast carcinoma (26\%), and lymphoma (13.0\%) were the most frequently diagnosed tumors. The median overall survival of patients from the initial diagnosis was 5 months (range: 1.0-96.0 months). Kaplan-Meier univariate analysis showed that survival was significantly related to the following prognostic factors: ECOG PS (hazard ratio [HR] 10.0, 95\% confidence interval [95\% Cl] 5.96 to 18.50, $\mathrm{p}<0.0001)$, primary cancer site (HR 1.99, 95\% $\mathrm{Cl} 1.23$ to $3.22, p<0.01$ ), positive pleural cytology ( $\mathrm{HR} 1.25,95 \% \mathrm{Cl} 0.88$ to $1.78, \mathrm{p}=0.04$ ), and positive histology ( $\mathrm{HR} 1.33,95 \% \mathrm{Cl} 0.97$ to $1.81, \mathrm{p}=0.04$ ). Other potential independent diagnostic factors that were examined did not affect survival. Cox regression analysis showed that only the ECOG PS was highly predictive of survival (HR 73.58, $95 \% \mathrm{Cl} 23.44$ to $230.95, \mathrm{p}<0.0001)$.

Conclusions: ECOG PS is an independent predictor of survival in patients with MPE at initial diagnosis. This prognostic factor can help physicians select patients for appropriate palliative treatment of this syndrome.

Keywords: Neoplasm, Malignant pleural effusion, Prognosis, Analysis, Survival

\section{Background}

A malignant pleural effusion (MPE) is often the first sign of cancer and it is a prognostic factor in patients with advanced disease. MPE can be a complication of any malignancy, but in patients with lung cancer, the frequency of MPE ranges from 7\% to 23\% [1] MPE is characteristic of advanced malignancies, but it may also appear in patients with a longer projected survival (e.g., those with lymphomas, including Hodgkin's disease, and breast carcinoma). The quality of life in patients with MPE is usually compromised because of distressing symptoms, such as coughing, dyspnea, and chest pain [2-4].

\footnotetext{
*Correspondence: mauro.zamboni@gmail.com

${ }^{1}$ Pulmonology and Thoracic Surgery Division, Hospital do Câncer I, Instituto Nacional de Câncer/Ministério da Saúde, Rio de Janeiro, RJ, Brazil

Full list of author information is available at the end of the article
}

The presence of MPE signifies an advanced stage of disease and usually indicates that death will likely result within a few months of the time pleural fluid is first detected $[4,5]$. Several treatments can relieve the respiratory symptoms of MPE. If the expected survival is short, less-invasive procedures are preferred for MPE [5-8].

Considering the cost of treatment for MPE and its potential complications, there are limited data that might assist chest physicians or surgeons in the precise prediction of survival time for patients with MPEs [7]. In this study, we investigated different variables that are potentially correlated with prognosis in a group of patients with MPE at the time of diagnosis [9-12]. This study aimed to determine the relative contributions of each

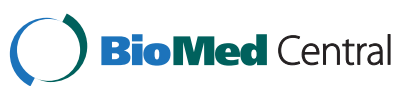

(c) 2015 Zamboni et al.; licensee BioMed Central. This is an Open Access article distributed under the terms of the Creative Commons Attribution License (http://creativecommons.org/licenses/by/4.0), which permits unrestricted use, distribution, and reproduction in any medium, provided the original work is properly credited. The Creative Commons Public Domain Dedication waiver (http://creativecommons.org/publicdomain/zero/1.0/) applies to the data made available in this article, unless otherwise stated. 
prognostic factor with respect to the survival time of patients with MPE.

\section{Methods}

A retrospective study was designed to identify prognostic factors in patients with MPE and a confirmed diagnosis of cancer. It was conducted from 2010 to 2012 at the Instituto Nacional do Cancer (INCA), Rio de Janeiro, Brazil. Data were collected from the medical records of patients who were identified through the cancer registry. One hundred and sixty-five patients with MPE who were referred to the hospital were included in this study. The Ethics Committee of INCA do Cancer, Rio de Janeiro, Brazil, approved this study in accordance with the recommendations found in the Declaration of Helsinki (\#162930; Jan 14, 2013).

At the INCA, detailed historical background was analyzed, physical examinations were conducted, and imaging evaluation was performed for each patient with clinical manifestations compatible with MPE. The presence of pulmonary or pleural masses, pulmonary atelectasis, or lymphadenopathy on chest radiography or/and computed tomography was considered suggestive of malignancy [5].

In addition, thoracocentesis was performed using standard methods. A pleural biopsy was performed using a Cope's needle and/or video-assisted thoracoscopic surgery. The definitions used for the diagnosis of a pleural effusion were based on previously published criteria [5]. When the diagnosis was unclear after thoracocentesis or closedneedle pleural biopsy, when the effusion persisted and symptoms increased, or when malignancy could not be differentiated from tuberculosis, the patient was referred for thoracoscopy or thoracotomy [5].

In all cases, the diagnosis of MPE was established by the presence of malignant cells in the pleural fluid upon thoracocentesis (positive pleural cytology) or evidence of a neoplasm upon pleural biopsy (histologically) [5].

The inclusion criteria for the study consisted of all patients with MPE who were not submitted to specific procedures, such as pleurodesis, pleuroscopy, or thoracoscopy. The exclusion criteria consisted of previous chemical pleurodesis and undiagnosed pleural effusion.

\section{Potential predictors of survival}

We considered 12 potential independent prognostic factors for survival in 165 patients with MPE from the INCA database. The database included demographic characteristics (age and sex), primary tumor site, glucose in the pleural fluid, levels of total protein and lactate dehydrogenase in the pleural fluid, cytological and histological results, percentage of lymphocytes and neutrophils in the pleural fluid, biochemical classification of pleural fluids into transudates or exudates [5,6], and Eastern
Cooperative Oncology Group Performance Status (ECOG PS). Briefly, ECOG PS consists of 5 grades: normal activity, grade 0 ; symptomatic but fully ambulatory, grade 1; symptomatic but bedridden less than $50 \%$ of the time, grade 2; bedridden more than $50 \%$ during the daytime, grade 3; completely (100\%) bedridden, grade 4; and dead, grade 5 [13-15] (Table 1). The survival time (measured in months) was defined and calculated from the day of pathological diagnosis to the day of death. No patient was censored.

\section{Statistical analysis}

Statistical analyses were performed using the MedCalc software, version 13.2.2, (Mariakerke, Belgium) [16]. Categorical variables are expressed as ratios of the two values (percentages). Continuous variables that were not normally distributed are expressed as medians after performing the D'Agostino-Pearson test.

The relationship between prognostic factors and outcome was modeled statistically by univariate KaplanMeier survival analysis [17]. For each potential predictor, stepwise modeling was performed to screen variables for inclusion into the model. A $\mathrm{p}$ value less than or equal to 0.10 by the chi-square test was required for a potential predictor to enter in the model. The multivariate Cox regression or proportional hazards regression method was used for investigating the effect of several independent variables (prognostic factors) for survival-time. The Cox model provides an estimate of the hazard ratio and its 95\% confidence intervals (CIs). The resultant risk variables in the Cox regression analysis were visualized by KaplanMeier curves. Statistical comparisons were performed using Kaplan-Meier method with log-rank test. A type I error probability of 0.05 (a two-tailed p-value) was used as the threshold for statistical significance. A 95\% CI was calculated to assess the clinical importance of the results.

The sample size that was necessary for this study was determined based on a publication by Altman and

Table 1 Performance scales: ECOG scores [14,15]

\begin{tabular}{ll}
\hline ECOG grade & ECOG status \\
\hline 0 & $\begin{array}{l}\text { Fully active, able to carry on all pre-disease } \\
\text { performance without restriction }\end{array}$ \\
& $\begin{array}{l}\text { Restricted in physically strenuous activity but } \\
\text { ambulatory and able to carry out work of a light or } \\
\text { sedentary nature, e.g., light house work, office work }\end{array}$ \\
& $\begin{array}{l}\text { Ambulatory and capable of all selfcare but unable } \\
\text { to carry out any work activities up and about } \\
\text { more than 50\% of waking hours }\end{array}$ \\
3 & $\begin{array}{l}\text { Capable of only limited selfcare, confined to bed } \\
\text { or chair more than 50\% of waking hours }\end{array}$ \\
& Completely disabled. Cannot carry on any selfcare. \\
& Totally confined to bed or chair \\
& Dead
\end{tabular}


Royston [17]. Survival analysis with the Kaplan-Meier method [18] can be used to study any sample size but is especially useful in studies with a small number of observations. In a regression model, the number of events should be at least 10 times the number of potential prognostic variables [19-21]. According to Royston and Altman [22] a prognostic model should not enter in clinical practice unless it demonstrates that it performs a useful role. Our statistical approach to external validation of a Cox model included: appropriate sample size, a multivariable model and its coefficients, creation of risk groups and Kaplan-Meier curves [19-22].

\section{Results}

Pleural effusion was the first manifestation of malignancy in approximately $15 \%$ of asymptomatic patients. The most common symptoms that were reported by patients were dyspnea (80\%) with a modified Medical Research Council (mMRC) score of 2 (moderate) to 4 (very severe), dull chest pain (30\%), and nonproductive cough $(10 \%)$. In $40 \%$ of patients with a personal history of cancer and with chronic symptoms of disease (longer than 30 days), many (90\%) patients had symptoms attributable to the cancer itself, such as fever, anorexia, weight loss, and malaise. A total of $52 \%$ of pleural effusions were large (affected two thirds or more of the hemithorax) and $33 \%$ were massive (opacified the entire hemithorax).

Table 1 shows the ECOG PS scores. Table 2 shows the characteristics of the 165 patients in the study population and the causes of MPE. Table 3 and Figure 1 show survival analysis according to the type of primary tumor. All of our patients had a median survival of 5 months (range: 1.0 - 96.0 months). Survival time was calculated in months rather than in days because it is a classical time variable according to multiple authors [20,21]. Patients with MPE from ovarian cancer showed better survival than those whose cancers were located in other anatomical sites (Table 3). Table 4 shows that some prognostic factors (variables) were not available in all cases. Table 4 shows the Kaplan-Meier univariate analysis, which showed that survival was significantly related to ECOG PS (chi-square $=195.40, \mathrm{p}<0.0001$ ), the site of the cancer (chi-square $=5.54, \mathrm{p}<0.01$ ), pleural cytology (chi-square $=4.20, \mathrm{p}=0.04$ ), and histology (chi-square $=4.09, \mathrm{p}=0.04$ ). With regard to the cancer site, only ovary tumors were significant compared with other malignant tumors. Other potential independent diagnostic factors that were examined did not appear to affect survival time.

Patients with an ECOG PS grade of 0 had the longest median survival (55 months), while those with a grade of $1,2,3$, or 4 had a median survival of $22,18,7$, and 1 month, respectively (Table 4). Patients with pleural
Table 2 Baseline characteristics of the study population ( $n=165)$

\begin{tabular}{ll}
\hline Characteristics & Values* \\
\hline Males, $\mathrm{n}(\%)$ & $77.0(47.0)$ \\
Females, $\mathrm{n}(\%)$ & $88.00(53.0)$ \\
Median age (range), years & $60.0(1.0-95.0)$ \\
Median pleural fluid glucose level (range), mg/dL & $96.0(2.0-440.0)$ \\
Median pleural fluid LDH level (range), U/L & $589.0(124.0-5506.0)$ \\
Median pleural fluid proteins (range), g/dL & $4.4(0.5-5.9)$ \\
Median pleural fluid neutrophils level (range), \% & $13.0(0.0-99.0)$ \\
Median pleural fluid lymphocytes level (range), \% & $75.0(1.0-100.0)$ \\
ECOG PS, grade 0 (\%) & $9(5.0)$ \\
ECOG PS, grade 1 (\%) & $9(5.0)$ \\
ECOG PS, grade 2 (\%) & $19(12.0)$ \\
ECOG PS, grade 3 (\%) & $47(29.0)$ \\
ECOG PS, grade 4 (\%) & $81(49.0)$ \\
Positive pleural cytology, $\mathrm{n}(\%)$ & $89(54.0)$ \\
Positive pleural histology, $\mathrm{n}(\%)$ & $83(50.0)$ \\
Exudate, $\mathrm{n}$ (\%) & $70.0(92.0)$ \\
\hline
\end{tabular}

*Missing data: ninety patients had missing data for glucose and protein levels; ninety three for LDH; one hundred sixteen for neutrophils; one hundred seventeen for lymphocytes and eighty nine for biochemical classification of pleural fluids. LDH: lactate dehydrogenase; PS: performance status.

effusion and ovarian cancer had the best median survival (21 months) compared with those with other primary tumors. The medial survival of patients with breast cancer was 6 months, and those with either lung cancer or lymphoma had a median survival of 4 months (Tables 3 and 4).

Cox proportional hazards analysis showed that ECOG PS (HR 73.58, p <0.0001) was the only independent prognostic factor affecting the survival of patients with MPE (Table 5). If the regression coefficient of the prognostic factor was positive, the risk of death (hazard) was higher (e.g., patients with higher values had a worse prognosis (Table 5). Patients with an ECOG score of 4 had worse survival than those with a better PS (ECOG

Table 3 Survival analysis according to primary tumor type

\begin{tabular}{lll}
\hline Type of primary tumor & $\begin{array}{l}\text { Patients, } \\
\text { number (\%) }\end{array}$ & $\begin{array}{l}\text { Median survival time, } \\
\text { months (range) }\end{array}$ \\
\hline Ovary & $10(6.0)$ & $21.0(5.0-46.0)$ \\
Breast & $43(26.0)$ & $6.0(1.0-58.0)$ \\
Lymphoma & $21(13.0)$ & $4.0(1.0-55.0)$ \\
Lung & $59(36.0)$ & $4.0(1.0-96.0)$ \\
Unknown & $08(5.0)$ & $4.0(1.0-13.0)$ \\
Other & $24(14.0)$ & $3.5(1.0-89.0)$ \\
Overall & $165(100.0)$ & $5.0(1.0-96.0)$ \\
\hline
\end{tabular}




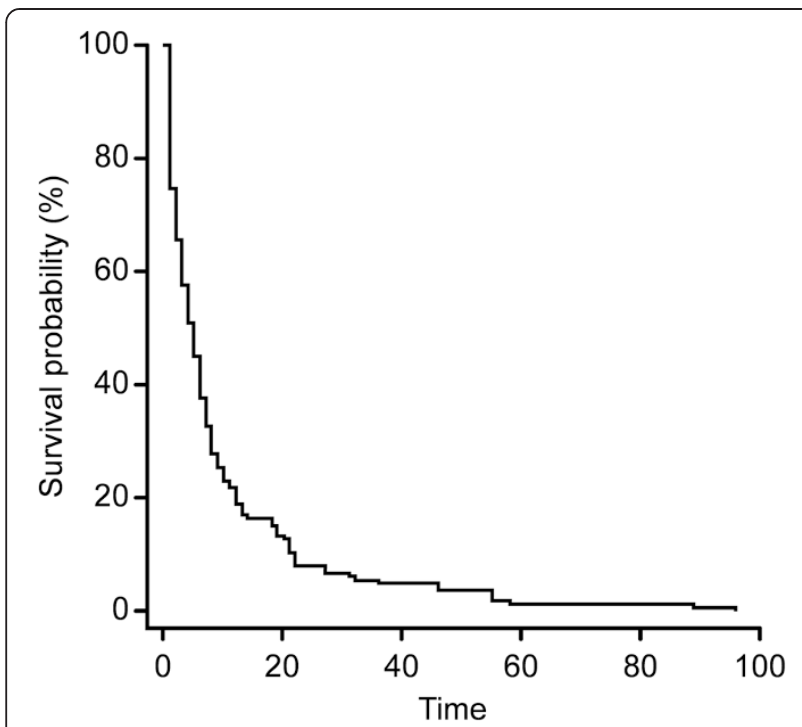

Figure 1 Kaplan-Meier curve showing the survival of the 165 patients. The median survival for all patients in the group was five months (95\% Cl; range: 1.0-96.0). (time in months).

score of 1 or 2), as shown by the Kaplan-Meier curve (Figure 2).

In summary, we found that the ECOG performance was a predictor of survival in patients with MPE from Brazil (Table 5).

\section{Discussion}

This retrospective study was designed to identify prognostic factors in patients with MPE and a confirmed diagnosis of cancer. A classical statistical model was appropriate to achieve this objective.

All of the patients in our study were diagnosed by conventional tests and procedures, and none received treatment for MPE (Table 2). The ratio of male to female subjects and the median age of 60 years are similar to the demographic characteristics as described by other authors in several series $[23,24]$.

An isolated small-sized MPE is a prognostic factor that is associated with a significantly worse survival in patients with lung cancer [25,26]. However, this is dependent on the stage and histopathological classification of the malignancy. Similar to several studies mentioned by Light $[7,8]$, lung carcinoma (36.0\%), breast carcinoma (26.0\%), and lymphoma (13.0\%) were the most frequent primary diagnoses in our series (Table 2). All of our patients with MPE and lung cancer had non-small-cell lung cancer. However, in a study by Jimenez et al. [27], massive MPEs (unlike small MPEs) were associated with a worse survival, independent of age and histological group.

According to The International Staging System for Lung Cancer [28], survival time for patients with MPE is worse in all stages of lung cancer [29]. Currently, the anatomical extent of MPE, as determined by the TNM staging system, is the most important prognostic tool for lung cancer. In 2007, The International Association for Study of Lung Cancer established that the presence of pleural effusion results in the designation of T4 disease. The presence of MPE is considered as metastatic disease (M1b) [30]. The survival time following diagnosis ranged from 1 to 96 months (median: 5 months) in the patients in our study (Table 3). Sears and Hajdu [31] demonstrated identical results to our study, with an average survival of 5 months or less following the diagnosis of MPE. In our study, patients with ovarian cancer and MPE had a longer survival (21 months, range: 5.0-46 months) than those with cancers of other primary sites (Table 3). The most frequent extra-abdominal metastatic site in cases of ovarian carcinoma is the pleural cavity $[32,33]$. The median survival in a group of 214 patients with ovarian carcinoma and MPE (stage IV) was 24 months $[34,35]$. In a study by Anevlavis et al. [24], patients with lymphoma had the best median survival (26 months), and those with ovarian and breast carcinomas had the second best survival times (18 and 15 months, respectively). In 120 cases of MPE reported by Martinez-Morangon et al. [9], the overall survival was 9 months.

In the current study, Kaplan-Meier univariate analysis showed that survival was significantly related to ECOG PS, primary cancer site, positive pleural cytology, and positive histology. Other potential independent diagnostic factors that were examined had no effect on survival (Table 4). Among 171 patients who were included in a study by von de Molengraft and Vooijs [36], only 4\% with positive pleural fluid cytology survived for 2 years after diagnosis.

In our study, Cox regression analysis demonstrated that only ECOG PS was highly predictive of survival. Several studies have demonstrated that performance status is a prognostic factor in cancer subjects [15,20-25]. The ECOG scale evaluates disease progression and quantifies the extent to which the disease affects the daily living abilities of the patient [15].

Our findings are in accordance with those of Burrows et al. [23] and Anevlavis et al. [24]. Both of them found that Performance Scale scores were predictive of survival in patients with MPE. Burrows et al. [23] found that only Karnofsky Performance Scale scores at the time of thoracoscopy were predictive of survival in patients with recurrent symptomatic MPE. Anevlavis et al. [24] concluded that prognostic factors affecting survival in patients with MPE were performance status (ECOG grade), primary tumor histology, and the neutrophil-to-lymphocyte ratio. Bielsa et al. [26] showed that tumor type and some biochemical features of pleural 
Table 4 Univariate analysis of the association between potential prognostic factors and survival for all 165 patients with malignant pleural effusions

\begin{tabular}{|c|c|c|c|c|c|}
\hline Prognostic factors & Categories & Patients (n) & Median survival time (months) $-(95 \% \mathrm{Cl})$ & Hazard ratio $(95 \% \mathrm{Cl})$ & $P$ value \\
\hline ECOG performance status & 0 & 9 & $55.0(46.0-58.0)$ & 1.0 & $<0.0001^{*}$ \\
\hline \multirow[t]{4}{*}{ Status } & 1 & 9 & $22.0(22.0-27.0)$ & $1.67(0.93-3.01)$ & \\
\hline & 2 & 19 & $18.0(13.0-19.0)$ & $2.13(1.24-3.63)$ & \\
\hline & 3 & 47 & $7.0(6.0-8.0)$ & $3.72(2.26-6.11)$ & \\
\hline & 4 & 81 & $1.0(1.0-2.0)$ & $10.50(5.96-18.50)$ & \\
\hline \multirow[t]{2}{*}{ Gender } & Male & 77 & $3.0(2.0-5.0)$ & $1.14(0.80-1.61)$ & \\
\hline & Female & 88 & $6.0(4.0-7.0)$ & 1.0 & 0.4105 \\
\hline Pleural fluid & $<13.0$ & 24 & $4.0(2.0-6.0)$ & 1.0 & \\
\hline Neutrophils (\%) & $\geq 13.0$ & 25 & $4.0(2.0-8.0)$ & $1.23(0.70-2.16)$ & 0.4091 \\
\hline \multirow[t]{2}{*}{ Pleural fluid glucose (mg/dL) } & $<96.0$ & 37 & $3.0(2.0-7.0)$ & $1.04(0.66-1.64)$ & \\
\hline & $\geq 96.0$ & 38 & $5.0(3.0-6.0)$ & 1.0 & 0.8323 \\
\hline \multirow[t]{2}{*}{ Pleural fluid LDH (U/L) } & $<589.0$ & 36 & $6.0(3.0-8.0)$ & 1.0 & \\
\hline & $\geq 589.0$ & 36 & $3.5(2.0-7.0)$ & $1.18(0.74-1.88)$ & \\
\hline Pleural fluid total & $<75.5$ & 24 & $4.5(2.0-7.0)$ & 1.0 & 0.4247 \\
\hline lymphocytes (\%) & $\geq 75.5$ & 24 & $3.5(2.0-7.0)$ & $1.14(0.64-2.01)$ & 0.6040 \\
\hline \multirow[t]{2}{*}{ Age (years) } & $<60$ & 79 & $5.0(3.0-7.0)$ & 1.0 & \\
\hline & $\geq 60$ & 86 & $4.0(3.0-6.0)$ & $1.08(0.79-1.47)$ & 0.5618 \\
\hline Pleural fluid total & $<4.4$ & 36 & $5.0(2.0-6.0)$ & 1.0 & \\
\hline proteins (g\%) & $\geq 4.4$ & 39 & $5.0(3.0-7.0)$ & $1.26(0.80-2.00)$ & 0.2590 \\
\hline \multirow[t]{2}{*}{ Histopathology } & Positive & 83 & $6.0(2.0-5.0)$ & $1.33(0.97-1.81)$ & \\
\hline & Negative & 82 & $4.0(4.0-9.0)$ & 1.0 & $0.0429^{*}$ \\
\hline \multirow[t]{2}{*}{ Cytology } & Positive & 89 & $6.0(4.0-8.0)$ & $1.25(0.88-1.78)$ & \\
\hline & Negative & 76 & $3.5(2.0-5.0)$ & 1.0 & $0.0403^{*}$ \\
\hline \multirow[t]{2}{*}{ Classification } & Exudate & 70 & $4.0(3.0-6.0)$ & $1.04(0.44-2.43)$ & \\
\hline & Transudate & 6 & $5.0(1.0-8.0)$ & 1.0 & 0.9161 \\
\hline \multirow[t]{2}{*}{ Cancer site } & Other & 155 & $4.0(3.0-6.0)$ & 1.0 & \\
\hline & Ovary & 10 & $21.0(8.0-22.0)$ & $1.99(1.23-3.22)$ & $0.0186^{*}$ \\
\hline
\end{tabular}

*p value (unadjusted), Chi-square $\leq .10=$ statistically significant variables; ECOG: Eastern Cooperative Oncology Group; LDH: lactate dehydrogenase; Cl: Confidence Interval.

effusion ( $\mathrm{pH}$ and concentrations of protein and lactate dehydrogenase) affect survival in patients with MPE.

Our findings - $\mathrm{pH}$ of pleural fluid and glucose levels are different from those of several other authors. In a study by Heffner et al. [37], the $\mathrm{pH}$ of pleural fluid was not predictive of the need for pleurodesis in selected patients, based on estimated survival. However, RodriguesPanadero and Lopez-Mejias [38] concluded that $\mathrm{pH}$ (lower than 7.35) and glucose levels (lower than $60.0 \mathrm{mg} / \mathrm{dL}$ ) in pleural fluid are risk factors for worse survival in patients with pleural cancer owing to extensive disease. Potential explanations for this discrepancy between different studies are the different regression models used for validation of

Table 5 Cox proportional regression analysis for statistically significant prognostic factors by univariate analysis in relation to the survival of all 165 patients with malignant pleura effusions

\begin{tabular}{lllll}
\hline Factors & Regression coefficient $(\mathbf{b})$ & Hazard ratios & $\mathbf{9 5 \%} \mathbf{C l}$ of HR & P value (adjusted)* \\
\hline ECOG PS & 4.2984 & 73.58 & $23.44-230.95$ & $<0.0001$ \\
Histopathology & 0.3752 & 1.45 & $0.86-2.43$ & .15 \\
Cytology & -0.1557 & 0.85 & $0.51-1.41$ & .54 \\
Cancer site & 0.053 & 1.05 & $0.52-2.14$ & .88 \\
\hline
\end{tabular}

*Over model fit: Null model -2 log likelihood: 1387.549. Full model -2 log likelihood: 1075.968, Chi-square $=311.58, p<0.0001$; Cl: confidence interval; ECOG: Eastern Cooperative Oncology Group. 


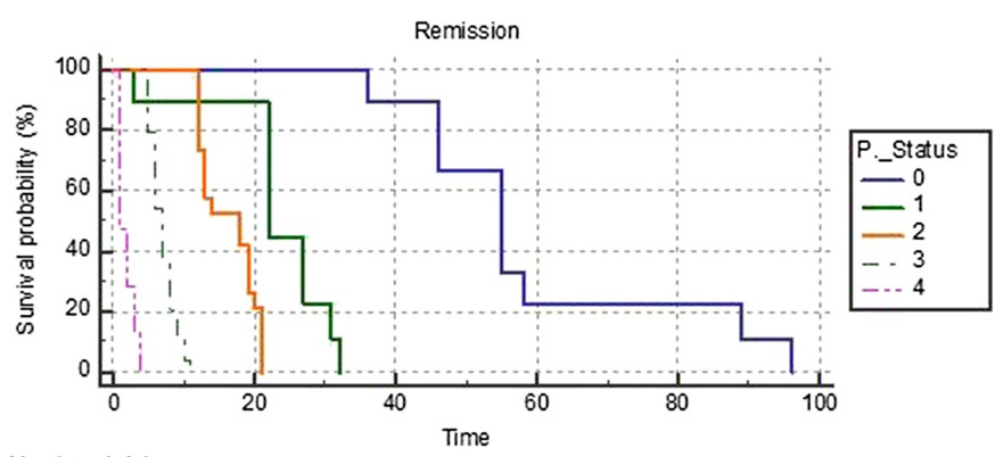

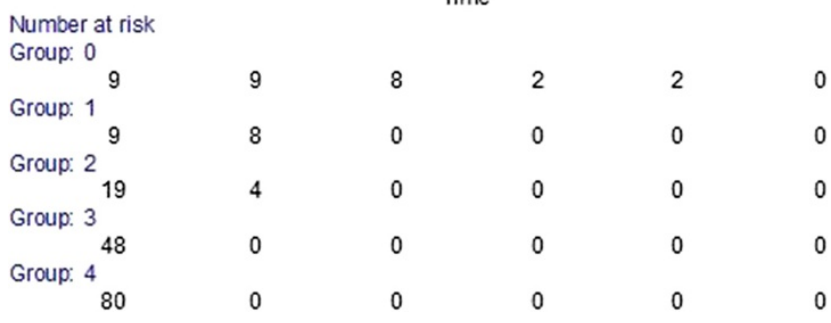

Figure 2 Kaplan-Meier curves showing the relationship between ECOG performance status (PS) and survival in patients with MPEs. A significant difference was observed in survival for patients with an ECOG grade of 1 to 4 (Chi-square $=242.15, p<0.0001$ ). ECOG scores of 1 (HR: 1.67, 95\% Cl: 0.93-3.01, p > .05), 2 (HR: 2.13, 95\% Cl: 1.24-3.67, p<.05), 3 (HR: 3.72, 95\% Cl: 2.26-6.11, p < .05) and 4 (HR: 10.50, 95\% Cl: 5.96-18.50, $p<.05$ ) are shown. (time in months).

the data, sample size, bias, and distinct populations used by other authors.

Our study adds important information to the existing literature. The projected survival time can help determine the most appropriate type of intrapleural therapy for MPE (e.g., pleurodesis vs. chronic drainage with indwelling catheters). There are several options for the treatment of MPE patients, some of which involve chemotherapy $[5,8]$, including therapeutic pleural thoracentesis, chemical pleurodesis with intercostal tube drainage or after thoracoscopy, a pleural-peritoneal shunt, a long-term ambulatory or indwelling pleural catheter for drainage, and open pleurectomy. Each of these procedures can successfully relieve dyspnea, but they are all associated with potential complications. When the expected survival is short, less invasive procedures should be considered (e.g., repeated thoracocentesis to relieve the symptoms) [7,8,39].

For patients with MPE and an anticipated survival time of 6 months, treatment with long-term indwelling pleural catheters is comparable to treatment with talc pleurodesis $[40,41]$. There are no robust data to support which of these two treatments is more effective at palliating symptoms and improving quality of life [40-43].

\section{Study limitations}

Our study has a few limitations as follows. Our data originated from a single referral center, the study was retrospective, there was a small number of patients in some categories, and there was a lack of patients with mesothelioma in the cohort. The absence of patients with mesothelioma in our cohort is probably owing to the fact that the incidence of this cancer is low in Brazil: 221 cases were reported from 2000 to 2011 [44].

\section{Conclusions}

This study shows that ECOG PS is an independent predictor of survival in patients with MPE at the time of the initial diagnosis. ECOG PS is a significant prognostic factor that can help physicians to select patients for appropriate palliative treatment of this syndrome. However, more studies are needed to conclude that one single factor can be a predictor of survival. Moreover, these studies will probably need to be confirmed by prospective studies to determine the best selection of treatment for providing the best quality of care.

\section{Competing interests}

The authors declare that they have no competing interests.

\section{Authors' contributions}

All the authors have contributed to a) the conception and design of the study; b) analysis and interpretation of data; and c) writing the article or revising it critically for important intellectual content. CTSJr performed the statistical analysis and interpreted the results. MMZ prepared the first draft of the paper. RB, ETC. and GPC were responsible for acquisition of clinical data and had full access to all of the data in the study and take responsibility for the integrity of the data and the accuracy of the data analysis. All authors read and approved the final manuscript. 


\section{Author details}

${ }^{1}$ Pulmonology and Thoracic Surgery Division, Hospital do Câncer I, Instituto Nacional de Câncer/Ministério da Saúde, Rio de Janeiro, RJ, Brazil.

${ }^{2}$ Pulmonology Division, Hospital Antonio Pedro, Universidade Federal Fluminense, Niterói, RJ, Brazil.

Received: 18 September 2014 Accepted: 17 March 2015

Published online: 28 March 2015

\section{References}

1. Froudarakis ME. Pleural effusion in lung cancer: more questions than answers. Respiration. 2012;83(5):367-76.

2. Chernow B, Sahn SA. Carcinomatous involvement of the pleura. An analysis of 96 patients. Am J Med. 1977;63(5):695-702.

3. Haas AR, Sterman DH, Musani Al. Malignant pleural effusions - management options with consideration of coding, billing, and a decision approach. Chest. 2007:132(3):1036-41.

4. Roberts ME, Neville E, Berrisford RG, Antunes G, Ali NJ. Management of a malignant pleural effusion: British thoracic society pleural disease guideline 2010. Thorax. 2010;65 Suppl 2:ii32-40.

5. Light RW. Pleural diseases. 6th ed. Philadelphia: Lippincott Williams \& Wilkins; 2013.

6. Ernam D, Ataly F, Hasanogley HC, Kaplan O. Role of biochemical tests in the diagnosis of exudative pleural effusions. Clin Biochem. 2005:38(1):19-23.

7. Ekpe EE, Ikpe M, IN U. Palliative treatment of malignant pleural effusion. Diag Ther Stud. 2013;2(1):8-20.

8. Hooper C, Lee YC, Maskell N. Investigation of a unilateral pleural effusion in adults: British thoracic society pleural disease guideline 2010. Thorax. 2010;65 Suppl 2:ii4-17.

9. Martinez-Moragon E, Aparicio J, Sanchis J, Menéndez R, Rogado MC, Sanchis F. Malignant pleural effusion: prognostic factors for survival and response to chemical pleurodesis in a series of 120 cases. Respiration. 1998;65(2):108-13.

10. Teixeira LR, Pinto JAF, Marchi E. Malignant pleural effusion. J Bras Pneumol. 2006;32 Suppl 4:S182-9.

11. Zarogoulidis K, Zarogoulidis P, Darwiche K, Tsakiridis K, Machairiotis N, Kougioumtzi K, et al. Malignant pleural effusion and algorithm management. J Thorac Dis. 2013:5 Suppl 4:S413-9.

12. Nam H-S. Malignant pleural effusion: medical approaches for diagnosis and management. Tuberc Respir Dis. 2014;76(5):211-7.

13. Michaud G, Berkowitz DM, Ernst A. Pleuroscopy for diagnosis and therapy for pleural effusions. Chest. 2010;138(5):1242-6.

14. Oken MM, Creech RH, Tormey DC, Horton J, Davis TE, McFadden ET, et al. Toxicity and response criteria of the Eastern cooperative oncology group. Am J Clin Oncol. 1982:5(6):649-55.

15. Orr ST, Aisner J. Performance status assessment among oncology patients: a review. Cancer Treat Rep. 1986:70(12):1423-9.

16. Garber C. MedCalc software for statistics in medicine. Clin Chem. 1998:44(5):1370

17. Altman DG, Royston P. What do we mean by validating a prognostic model? Statist Med. 2000;19(4):453-73.

18. Kaplan E, Meier P. Nonparametric estimation from incomplete observations. J Am Stat Assoc. 1958;53(282):457-81.

19. Harrell F, Lee KL, Califf RM, Pryor DB, Rosati RA. Regression modelling strategies for improved prognostic modelling. Stat Med. 1984;3(2):143-52.

20. Bustamante-Teixeira MT, Faerstein E, Latorre MR. Survival analysis techniques. Cad Saude Publica. 2002;18(3):579-94.

21. Mallet $S$, Royston $P$, Waters $R$, Dutton $S$, Altman DG. Reporting performance of prognostic models in cancer: a review. BMC Med. 2010;8:21-31.

22. Royston P, Altman DG. External validation of a Cox prognostic model: principles and methods. BMC Med Res Methodol. 2013;13:33-9.

23. Burrows $\mathrm{CM}$, Mathews $\mathrm{C}$, Colt HG. Predicting survival in patients with recurrent symptomatic malignant pleural effusions. Chest. 2000;117(1):73-8.

24. Anevlavis S, Kouliatsis G, Sotiriou I, Koukourakis MI, Archontogeorgis K, Karpathiou G, et al. Prognostic factors in patients presenting with pleural effusion revealing malignancy. Respiration. 2014;87(4):311-6.

25. Clive AO, Kahan BC, Hooper CE, Bhatnagar R, Morley AJ, Zahan-Evans N, et al. Predicting survival in malignant pleural effusion: development and validation of the LENT prognostic score. Thorax. 2014:69:1098-104.

26. Bielsa S, Salud A, Martínez M, Esquerda A, Martín A, Rodríguez-Panadero F, et al. Prognostic significance of pleural fluid data in patients with malignant effusion. Eur J Int Med. 2008:19:334-9.
27. Naito T, Satoh H, Ishikawa H, Yamashita YT, Kamma H, Takahashi H, et al. Pleural effusion as a significant prognostic factor in non-small cell lung cancer. Anticancer Res. 1997;17(6):4743-6.

28. Ryu JS, Ryu HJ, Lee SN, Memon A, Lee SK, Nam HS, et al. Prognostic impact of minimal pleural effusion in non-small cell lung cancer. J Clin Oncol. 2014:32(9):960-7.

29. Jimenez D, Diaz G, Gil D, Cicero A, Perez-Rodriguez E, Sueiro A, et al. Etiology and prognostic significance of massive pleural effusions. Respir Med. 2005;99(9):1183-7.

30. Mountain CF. A new international staging system for lung cancer. Chest. 1986;89(4 Suppl):225S-33.

31. Sugiura S, Ando Y, Minami H, Ando M, Sakai S, Shimokata K. Prognostic value of pleural effusion in patients with non-small cell lung cancer. Clin Cancer Res. 1997;3(1):47-50.

32. Goldstraw P, Crowley J, Chansky K, Giroux DJ, Groome PA, Rami-Porta R, et al. The IASLC lung cancer staging project: proposals for the revision of the TNM stage groupings in the forthcoming (seventh) edition of the TNM classification of malignant tumours. J Thorac Oncol. 2007;2(8):706-14.

33. Porcel JM, Diaz JP, Chi DS. Clinical implications of pleural effusions in ovarian cancer. Respirology. 2012;17(7):1060-7.

34. Sears D, Hadju SI. The cytologic diagnosis of malignant neoplasms in pleural and peritoneal effusions. Acta Cytol. 1987;31(2):85-97.

35. Winberger $P$, Wehling $M$, Lehmann N, Kimmig R, Schmalfeldt B, Burges A, et al. Influence of residual tumor on outcome in ovarian cancer patients with FIGO stage IV disease. Ann Surg Oncol. 2010;17(6):1642-8.

36. von de Molengraft FJJM, Vooijs GP. Survival of patients with malignancyassociated effusions. Acta Cytol. 1989;33(6):911-6.

37. Heffner JE, Nieterr PJ, Barbieri C. Pleural fluid $\mathrm{pH}$ as a predictor of survival for patients with malignant pleural effusions. Chest. 2000;117(1):79-86.

38. Rodriguez-Panadero F, Lopez-Mejias J. Survival time of patients with pleural metastatic carcinoma predicted by glucose and $\mathrm{pH}$ studies. Chest. 1989;95(2):320-4.

39. Huggins JT, Doelken P, Sahn SA. Intrapleural therapy. Respirology. 2011;16(6):891-9.

40. Davies HE, Mishra EK, Kahan BS, Wrightson JM, Stanton AE, Guhan A, et al Effect of an indwelling pleural catheter vs chest tube and talc pleurodesis for relieving Dyspneia in patients with malignant pleural effusion. JAMA. 2012;307(22):2383-9.

41. Demmy TL, Gu L, Burkhalter JE, Toloza EM, D'Amico TA, Sutherland S, et al. Optimal management of malignant pleural effusions (results of CALGB 3012). J Nat Comp Canc Netw. 2012;10:975-82.

42. Olden AM, Holloway R. Treatment of malignant pleural effusion: PleuRx catheter or talc pleurodesis? a cost-effectiveness analysis. J Palliat Med. 2010:13(1):59-65.

43. MacEachern P, Tremblay A. Pleural controversy: pleurodesis versus indwelling pleural catheters for malignant effusions. Respirology. 2011;16(5):747-54.

44. Estimativa de Câncer 2014 in http://www.inca.gov.br/estimativa2014/.

\section{Submit your next manuscript to BioMed Central and take full advantage of:}

- Convenient online submission

- Thorough peer review

- No space constraints or color figure charges

- Immediate publication on acceptance

- Inclusion in PubMed, CAS, Scopus and Google Scholar

- Research which is freely available for redistribution 